\title{
Ureteroscopy for Stone Disease in Paediatric Population is Safe and Effective in Medium-Volume and High-Volume Centres: Evidence from a Systematic Review
}

\author{
Shazna Rob ${ }^{1}$ • Patrick Jones ${ }^{1}$ - Amelia Pietropaolo ${ }^{1} \cdot$ Stephen Griffin $^{2}$. \\ Bhaskar K. Somani ${ }^{1}$
}

Published online: 18 October 2017

(C) The Author(s) 2017. This article is an open access publication

\begin{abstract}
Purpose of Review The incidence of urinary stone disease among the paediatric population is increasing. Whilst there has been a rise in the number of original studies published on ureteroscopy (URS) in children, critical review still remains under-reported.

Recent Findings A Cochrane style systematic review was performed to identify all original articles on URS (minimum of 25 cases) for stone disease in paediatric patients between Jan. 1996 and Dec. 2016. Based on the number of reported cases, centres were divided into medium (25-49 cases) and high ( $\geq 50$ cases) volume studies.

Thirty-four studies (2758 children) satisfied our search criteria and were included in this review. The mean stone size was $8.6 \mathrm{~mm}$ with an overall stone-free rate (SFR) of $90.4 \%$ (range 58-100). Medium-volume centres reported a mean SFR of $94.1 \%$ (range $87.5-100$ ), whilst high-volume centres
\end{abstract}

This article is part of the Topical Collection on Paediatric Urology

Bhaskar K. Somani

bhaskarsomani@yahoo.com

Shazna Rob

sr2g11@soton.ac.uk

Patrick Jones

patrick.jones1@nhs.net

Amelia Pietropaolo

ameliapietr@gmail.com

Stephen Griffin

stephengriffin69@googlemail.com

1 Department of Urology, University Hospital Southampton, Southampton, UK

2 Department of Paediatric Urology, University Hospital Southampton, Southampton, UK reported a mean SFR of $88.1 \%$ (range 58-98.5). Mean number of sessions to achieve stone-free status in medium-volume and high-volume groups was 1.1 and 1.2 procedures/patient respectively. The overall complication rate was $11.1 \%$ (327/ 2994). Breakdown by Clavien grade was as follows: Clavien I $69 \%$ and Clavien II/III 31\%. There were no Clavien IV/V complications, and no mortality was recorded across any of the studies. The overall failure to access rate was $2.5 \%$ (76/ 2944).

Medium-volume and high-volume studies had overall complication rates of $6.9 \%(37 / 530)$ and $12.1 \%$ (287/2222) respectively, but there was no significant difference in major or minor complications between these two groups.

Summary Ureteroscopy is a safe and effective treatment for paediatric stone disease. Medium-volume centres can achieve equally high SFRs and safety profiles as high-volume centres. Despite the rarity of paediatric stone disease, our findings might increase the uptake of paediatric URS procedures.

Keywords Paediatric $\cdot$ Ureteroscopy $\cdot$ Volume · Complications $\cdot$ Success $\cdot$ Urolithiasis

\section{Introduction}

The incidence of urinary stone disease among the paediatric population is rising [1]. This has led to the development of minimally invasive and effective endourological interventions that can yield a high stone clearance whilst preserving renal function with low morbidity in these children. In the adult population, application of ureteroscopy (URS) globally has expanded over $200 \%$ in the past decade [2•]. This shift owes largely to major advances in surgical technique, laser technology and equipment minimisation. Similar changes have been mirrored in the management of paediatric stone disease, 
although Ritchey et al. first described URS in a young child in 1988 [3]. Whilst there has been a rise in the number of original studies published on this topic, critical evaluation of the safety and efficacy of URS for paediatric cases remains under-reported. The objective of this study was to therefore formally appraise the existing evidence. Furthermore, given the dissemination of URS and that its uptake is no longer limited to specialist centres, we sought to determine if there were any differences in clinical outcomes among these high-volume centres compared to those reporting medium volumes.

\section{Material and Methods}

\section{Evidence Acquisition: Criteria for Considering Studies for This Review}

\section{Inclusion Criteria}

- Studies reporting on outcomes following ureteroscopy in paediatric populations

- Patients aged $\leq 18$

\section{Exclusion Criteria}

- Study sample size $<25$ patients

- Non-English language articles

- Animal studies

\section{Search Strategy and Study Selection}

A Cochrane style search was performed to identify all original articles investigating ureteroscopy in paediatric patients (Fig. 1). The Preferred Reporting Items for Systematic Reviews and Meta-Analyses (PRISMA) checklist was adhered to accordingly. Sensitive and customised search strategies were applied to the following online bibliographic databases: PubMed/MEDLINE, EMBASE, CINAHL and The Cochrane Central Register of Controlled Trials, whilst citation lists and study references were also evaluated.

Search terms included (but not limited to) 'ureteroscopy', 'URS', 'retrograde intra-renal surgery', 'RIRS', 'paediatric', 'pediatric', 'urolithiasis' and 'stones'. Boolean operators (AND, OR) were incorporated to refine the search. Medical subject headings (MeSH) included (not limited to) [Urinary calculi], [Ureteroscopy], [Lasers], [Child] and [Nephrolithiasis].

All study types were considered for potential inclusion. A time restriction was applied to include relevant studies published between January 1990 and December 2016. Paediatric age was defined as 18 years or less. Studies combining adult and paediatric populations with no breakdown of results were excluded.

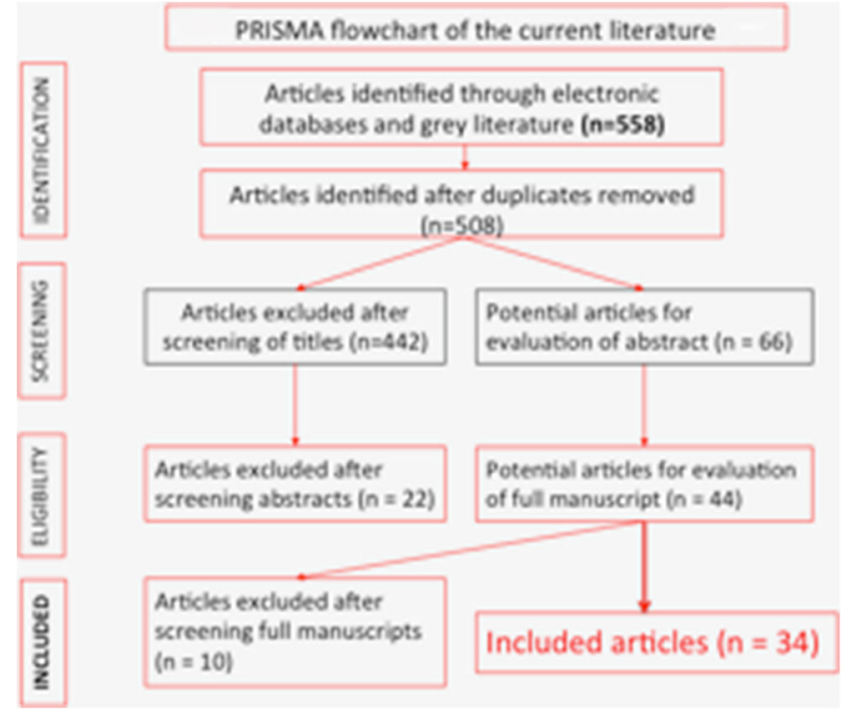

Fig. 1 PRISMA flow chart of the current literature

\section{Outcomes of Interest}

Primary Outcomes

- Procedure-related complications (graded according to Clavien-Dindo system)

- Stone-free rates (SFRs)

\section{Secondary Outcomes}

- Comparison of outcomes for ureteroscopy performed in medium-volume centres (reporting 25-49 procedures) and high-volume centres (reporting $\geq 50$ procedures).

\section{Data Extraction and Analysis}

Both the search process and data extraction were performed by two authors (SR, PJ) independently and overseen by the senior author (BKS). Information was also collected on patient characteristics, total number of procedures performed and stone location. For the purposes of this review, centres reporting on 25-49 procedures were termed 'medium-volume' and $\geq 50$ procedures as 'high-volume' centres. We did not include studies from centres that reported on $<25$ procedures, which were deemed to be low-volume centres. Complications recorded intra-operatively or within the study follow period were included for analysis.

Chi-squared test and independent $t$ test were used for dichotomous and continuous data respectively (SPSS version 21). 
Table 1 Demographics of patients reported in the studies

\begin{tabular}{|c|c|c|c|c|c|c|c|}
\hline Author & Journal & Year & Country & $\begin{array}{l}\text { No. of } \\
\text { procedures }\end{array}$ & $\begin{array}{l}\text { Sample size } \\
\text { (male/female) }\end{array}$ & $\begin{array}{l}\text { Mean age } \\
\text { (years) (range) }\end{array}$ & $\begin{array}{l}\text { Mean stone size } \\
\text { (range) }(\mathrm{mm})\end{array}$ \\
\hline \multicolumn{8}{|c|}{ Medium-volume centres } \\
\hline Schuster [6] & Journal of Urology & 2002 & USA & $27^{*}$ & $25(13 / 12)$ & $9.2(3$ to 14$)$ & $6(2-12)$ \\
\hline Dogan [7] & BJU International & 2004 & Turkey & $35^{*}$ & $35(15 / 20)$ & $6.2(1$ to 14$)$ & $8(4-15)$ \\
\hline Satar [8] & Journal of Urology & 2004 & Turkey & $33^{*}$ & $33(\mathrm{NR})$ & $7.4(0.75$ to 15$)$ & $5.3(3-10)$ \\
\hline Al-Busaidy [9] & BJU International & 2004 & Oman & $28^{*}$ & $26(14 / 12)$ & $6.5(2-12)$ & $12.1(4-22)$ \\
\hline Thomas [12] & J Urol & 2005 & USA & $33 *$ & $29(15 / 14)$ & $7.8(0.4-12)$ & $6(3-9)$ \\
\hline El-assmy [13] & Journal of Endourology & 2006 & Egypt & $33^{*}$ & 32 (NR) & $8.7(2-15)$ & $7(4-15)$ \\
\hline Ertuhan [16] & Journal of Endourology & 2007 & Turkey & $41^{*}$ & $41(16 / 25)$ & $9.5(3-15)$ & $5.6(4-10)$ \\
\hline Corcoran [17] & J Urol & 2008 & USA & $30^{*}$ & 30 & $9.7(2.2-14.4)$ & $8.8(1.5-25)$ \\
\hline Yeow [20] & J Indian Assoc Pediatr Surg & 2009 & Australia & $26^{*}$ & $26(14 / 12)$ & $8.2(0.25-15)$ & $10.3(3-21)$ \\
\hline Chedgy [31] & Urologia Internationalis & 2015 & UK & $32 *$ & $21(13 / 8)$ & $8.6(1.4-16)$ & $9.6(5-20)$ \\
\hline Featherstone $[33 \bullet \bullet]$ & Journal of Paediatric urology & 2016 & UK & $35^{*}$ & $18(7 / 11)$ & $10.4(3.6-15)$ & $13.2(10-25)$ \\
\hline Iqbal [35] & Urology & 2016 & Pakistan & $37 *$ & $37(25 / 12)$ & 8.37 (NR) & $10.01(\mathrm{NR})$ \\
\hline Utangac [36] & JCPSP & 2016 & Turkey & $34 *$ & $34(22 / 12)$ & $0.8(0.33-12)$ & NR \\
\hline \multicolumn{8}{|l|}{ High-volume centres } \\
\hline Al Busaidy [4] & British Journal of Urology & 1997 & Oman & $50 * *$ & $43(29 / 14)$ & $6.2(0.5-12)$ & $12.6(4-22)$ \\
\hline Bassiri [5] & Journal of Endourology & 2002 & Iran & $66^{* *}$ & $66(\mathrm{NR})$ & $9(2-15)$ & $8(5-15)$ \\
\hline Minevich [10] & Journal of Urology & 2005 & USA & $81^{* *}$ & $71(39 / 32)$ & $7.5(1-12)$ & NR \\
\hline Raza [11] & Journal of Endourology & 2005 & UK & $52 * *$ & $35(25 / 10)$ & $5.9(0.9-15)$ & $8.8(3-20)$ \\
\hline Gedik [14] & $\begin{array}{l}\text { International Urology and } \\
\text { Nephrology }\end{array}$ & 2007 & Turkey & $54 * *$ & $54(32 / 22)$ & $8.5(1-16)$ & $7.1(4-12)$ \\
\hline Smaldone [15] & Journal of Urology & 2007 & USA & $115^{* *}$ & $100(42 / 58)$ & 13.2 & 8.3 \\
\hline Tanaka [18] & Journal of Urology & 2008 & USA & $52 * *$ & $50(31 / 19)$ & $7.9(1.2-13.6)$ & $8(1-16)$ \\
\hline Kim [19] & Journal of Urology & 2008 & USA & $170 * *$ & $167(89 / 78)$ & $5.2(0.25-18)$ & NR \\
\hline Tanriverdi [21] & Paediatric Surgery International & 2010 & Turkey & $65^{* *}$ & $65(39 / 26)$ & $9.1(2-16)$ & $6.1(3-24)$ \\
\hline Turunc [22] & Journal of Endourology & 2010 & Turkey & $66^{* *}$ & $61(\mathrm{NR})$ & $8.1(0.5-16)$ & $9.5(3-30)$ \\
\hline Ghazaleh [23] & $\begin{array}{l}\text { Saudi Journal of Kidney } \\
\text { Diseases and } \\
\text { Transplantation }\end{array}$ & 2011 & Jordan & $78 * *$ & $56(38 / 18)$ & $8.2(6-14)$ & $8.2(4-20)$ \\
\hline Nerli [24] & Journal of Endourology & 2011 & India & $88 * *$ & $80(69 / 11)$ & $9.5(6-12)$ & $12(9-15)$ \\
\hline Dogan [25•] & Journal of Urology & 2011 & Turkey & $660 * *$ & $642(265 / 377)$ & $7.5(0.33-17)$ & $10.2(7-16)$ \\
\hline Yucel [26] & World journal of urology & 2011 & Turkey & $54 * *$ & $48(28 / 20)$ & $7.6(0.75-18)$ & $8.9(\mathrm{NR})$ \\
\hline Atar [27] & Urological research & 2012 & Turkey & $69 * *$ & $64(23 / 41)$ & $4.3(\mathrm{NR})$ & NR \\
\hline Resorlu [28] & Urology & 2012 & Turkey & $95 * *$ & $95(53 / 42)$ & $9.3(1-17)$ & 14.3 (NR) \\
\hline Jurkiewicz [29] & Urolithiasis & 2013 & Germany & $157 * *$ & $126(66 / 60)$ & $7.5(0.8-17)$ & 7.2 \\
\hline Ezkurt [30] & Urolithiasis & 2013 & Turkey & $65^{* *}$ & $65(31 / 34)$ & $4.3(0.5-7)$ & $14.66(7-30)$ \\
\hline Sen [32] & Journal of Paediatric urology & 2015 & Turkey & $175 * *$ & $175(101 / 74)$ & $4(\mathrm{NR})$ & $9.6(5-20)$ \\
\hline Gokce [34] & Urology & 2016 & Turkey & $116^{* *}$ & $116(78 / 38)$ & 9.5 (NR) & 9.4 (NR) \\
\hline \multicolumn{8}{|l|}{ Other } \\
\hline Guven [37] & Urology & $2016^{\mathrm{a}}$ & $\begin{array}{l}\text { Global } \\
\quad \text { (over } 23 \text { countries) }\end{array}$ & 192 & $192(109 / 83)$ & $10.3(\mathrm{NR})$ & $4.56(1.96-9.43)$ \\
\hline
\end{tabular}

\footnotetext{
${ }^{*}$ Medium volume centre; ${ }^{* *}$ High volume centre
}

${ }^{\mathrm{a}}$ Multicentric study

\section{Results}

Thirty-four studies [4-24, 25•, 26-32, 33••, 34-37] satisfied our search criteria and were included in this review (Table 1). These were all published between 1996 and 2016. A total of
2758 children underwent URS for urinary stone disease. The mean age was 7.8 years (range $0.25-18$ ) with a male to female ratio of $1: 1$. No significant difference in age was present between these groups $(p>0.05)$. The mean stone size was $8.6 \mathrm{~mm}$ (range 1-30). Breakdown by stone location was as 


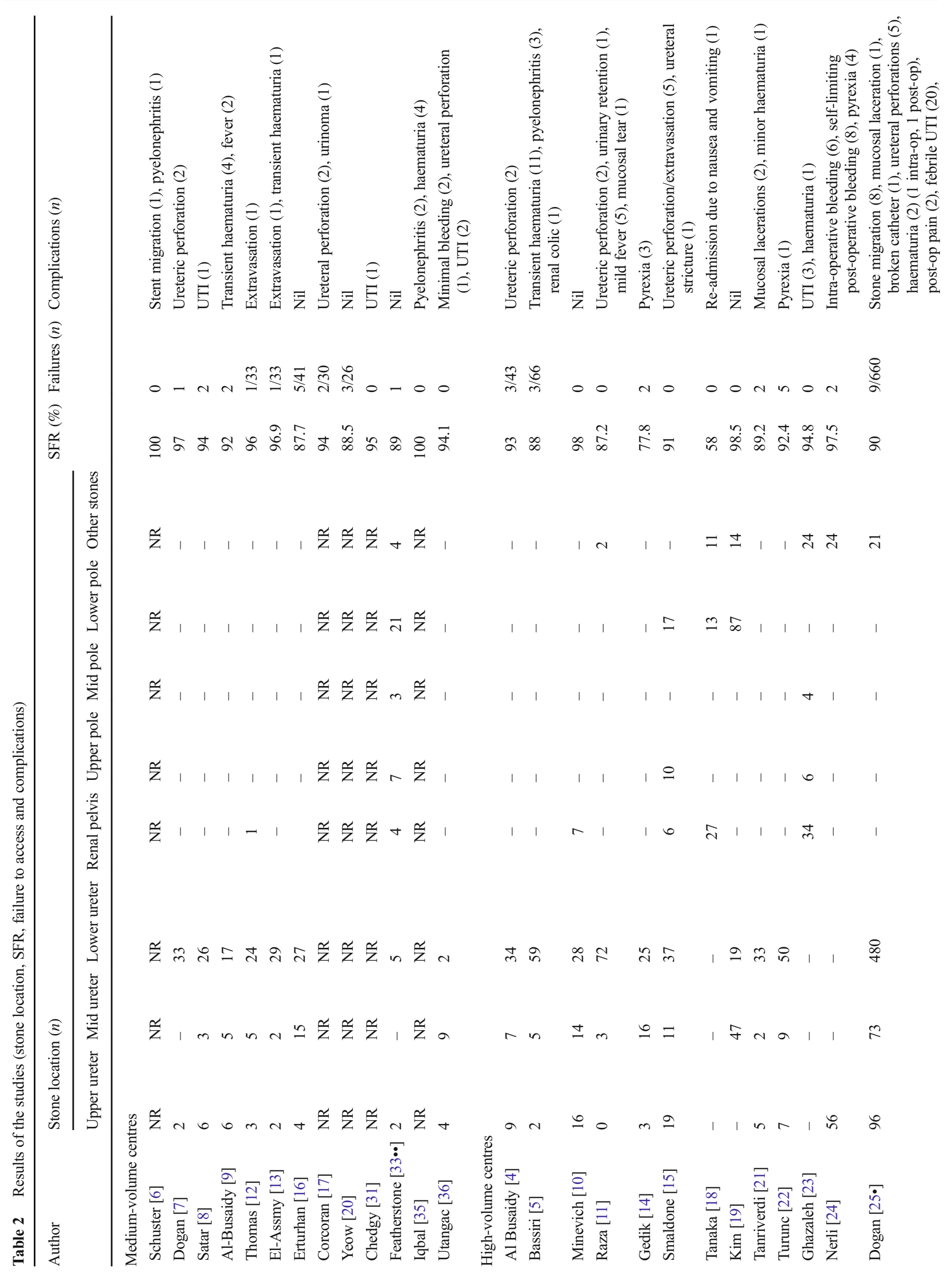




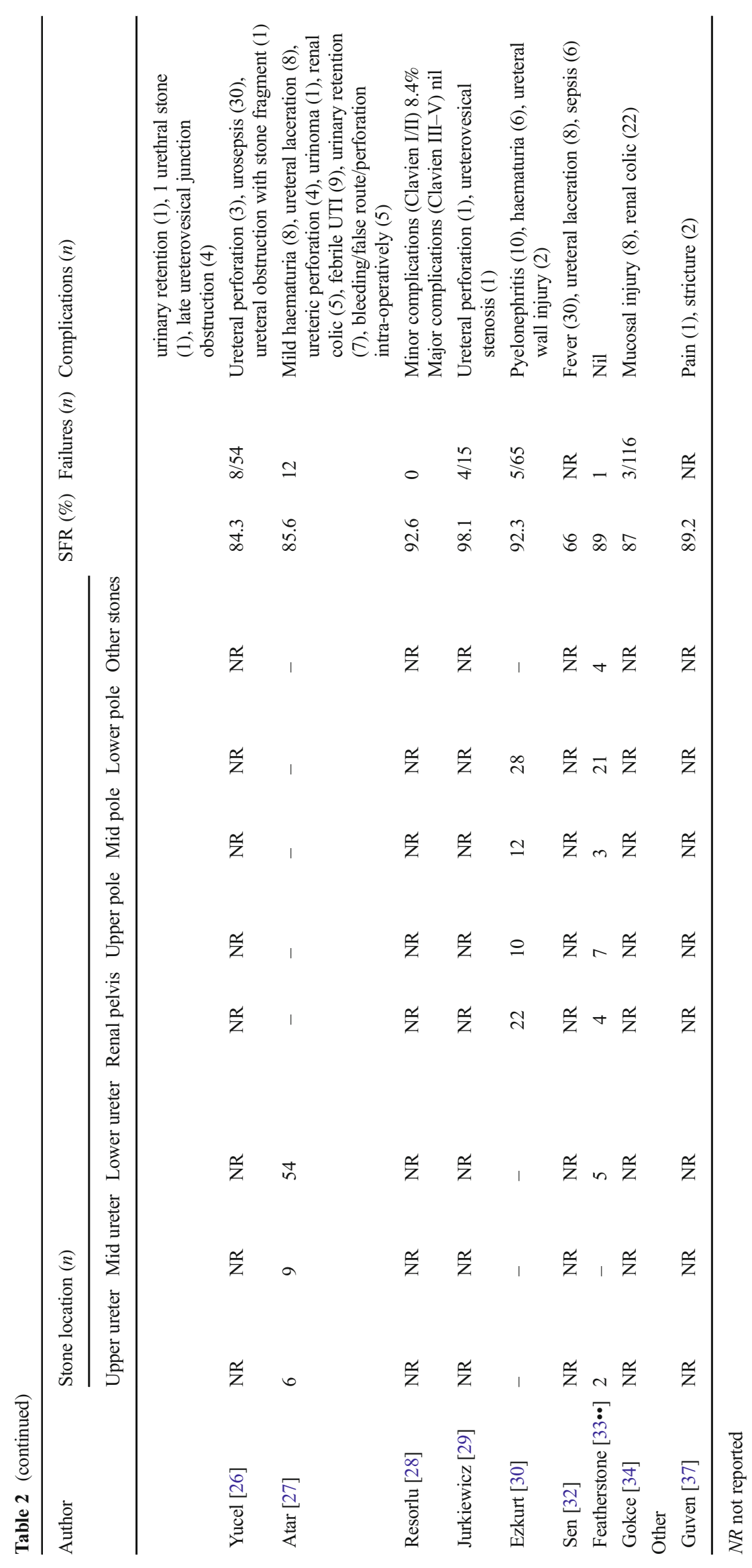


follows: upper ureter $13.3 \%$, mid ureter $12.5 \%$, lower ureter $56.6 \%$, renal pelvis $3.5 \%$, upper pole $1.2 \%$, mid pole $1 \%$, lower pole $8.4 \%$, other $3.5 \%$.

Overall, 2944 procedures were performed with a mean caseload of 87 procedures per study (range 25-660). There were 13 and 20 studies in the medium-volume $[6-9,12,13,16,17,20$, $31,33 \bullet \bullet, 35,36]$ and high-volume [4, 5, 10, 11, 14, 15, 18, 19, 21-24, 25 •, 26-30, 32, 34] groups respectively. Given the paediatric data from the CROES database that was gathered from over 50 centres, it was excluded from this subclassification although the data was used for the overall results [37].

\section{Outcome Measures}

All studies reported SFR, with an overall SFR of $90.4 \%$ (range 58-100). Medium-volume centres reported a mean SFR of 94.1\% (range 87.5-100). High-volume centres reported a mean SFR of $88.1 \%$ (range 58-98.5). Mean number of sessions to achieve stone-free status in medium-volume and high-volume groups was 1.1 and 1.2 procedures/patient respectively (Table 2).

Across all the included studies, the overall complication rate was $11.1 \%$ (327/2994). Breakdown by Clavien grade was as follows: Clavien I $69 \%$ and Clavien II/III $31 \%$ (Table 3). There were no Clavien IV/V complications, and no mortality was recorded across any of the studies.

Medium-volume and high-volume studies had overall complication rates of $6.9 \%(37 / 530)$ and $12.1 \%(287 / 2222)$ respectively. There was no significant difference in major or minor complications between these two groups. The overall failure rate was $2.5 \%(76 / 2944)$. Most of them were due to failure to access the paediatric ureter.

\section{Discussion}

\section{Findings and Implications of Our Review}

This is the largest review on paediatric URS to date and reveals an overall SFR of $90.4 \%$ and an overall complication rate of $11.1 \%$. Over two thirds of these complications were Clavien I. Importantly, there was no significant difference in SFR or complication rates between medium-volume and high-volume centres.

\section{PCNL in Paediatric Population}

Percutaneous nephrolithomy (PCNL) and shockwave lithotripsy (SWL) represent the key alternative interventions to URS. Whilst the former can achieve high stone-free rates in a single procedure and is not limited by failure to access the ureter such as can occur in URS, it carries a worse morbidity profile, notably in the form of haemorrhagic complications. Bhageria et al. reported transfusion rate of $9 \%$ in their retrospective cohort of 95 children undergoing PCNL [38]. Miniaturisation of standard equipment (<24Fr) has delivered a key strategy for improving its safety status both in adult and paediatric populations. Multiple studies have confirmed higher incidence of haematuria and renal extravasation associated with the use of larger tract sizes [39]. PCNL can now even be delivered in the 'micro' format using a 4.5Fr tract with final SFRs
Table 3 Complications reported in studies from medium-volume and high-volume centres

\begin{tabular}{|c|c|c|c|}
\hline \multirow[t]{2}{*}{ Nature of complication } & \multirow[t]{2}{*}{ Clavien grade } & \multicolumn{2}{|c|}{ Number of complications $(n)$} \\
\hline & & Medium volume & High volume \\
\hline Post-operative renal colic & I & - & 2 \\
\hline Haematuria & I & 9 & 36 \\
\hline UTI/pyelonephritis & I & 4 & 72 \\
\hline Mild fever/pyrexia post-operatively & I & 12 & 34 \\
\hline Urinary retention & $\mathrm{I}$ & 1 & 8 \\
\hline Post-operative renal colic & $\mathrm{I}$ & - & 29 \\
\hline Re-admission due to nausea and vomiting & I & - & 1 \\
\hline Urethral stone & I & - & 1 \\
\hline Late ureterovesical junction obstruction & III & - & 5 \\
\hline Stent migration & III & 1 & 8 \\
\hline Ureteral strictures & III & - & 1 \\
\hline Post-operative ureteral stone & III & - & - \\
\hline Broken catheter & III & - & 1 \\
\hline $\begin{array}{l}\text { Intra-operative bleeding/false passage/ureteral } \\
\text { perforation/tear/laceration/submucosal wire }\end{array}$ & III & 10 & 63 \\
\hline Stone migration & III & - & 8 \\
\hline Total & - & 37 & 269 \\
\hline
\end{tabular}


reported between 80 and $100 \%$ [39]. Its use for treatment of ureteric stones however remains less valuable [40].

\section{SWL in Paediatric Population}

Shockwave wave lithotripsy is a minimally invasive option, with a relatively short learning curve and generally minor complications [40]. It has traditionally been the first-line intervention for paediatric stone disease. However, it can necessitate multiple sittings and in children generally requires administration of general anaesthetic. Additionally, SFRs are less predictable with stone recurrences commonly due to incomplete stone clearances [41].

\section{Future Trends in Ureteroscopy}

With increased uptake of URS, it looks set to reach an increasing number of endourological milestones. URS has also undergone the miniaturisation process. Utangac et al. recently reported using a micro-ureteroscope (4.5Fr along entire length) in 11 children with a median stone size of $10.5 \mathrm{~mm}$ [41]. Stone-free status was achieved in all cases. There were no intra-operative complications and only one case of transient haematuria post-operatively. This novel modification may prove extremely valuable and allow better ureteric cannulation/navigation with fewer cases of access failure. However, further studies are needed comparing it with standard URS.

\section{Limitations of Our Study}

Whilst this study represents the largest review to date on paediatric URS, there are certain limitations, which the authors acknowledge. Results have been included from predominantly retrospective studies with age ranges spanning development of the urinary tract from infancy to adult state. The heterogeneity of available evidence did not allow for formal metaanalysis to be performed. In comparison, we did find a relatively higher stone-free rate with lower complications in medium-volume centres. However, we feel that this might reflect higher complexity of cases in established endourology high-volume centres. Similarly, training and guidance on 'tips and tricks' of ureteroscopy might help improve outcomes in less well-established paediatric stone centres [42, 43].

\section{Conclusion}

URS is a safe and effective treatment for the treatment of stone disease among the paediatric population. Medium-volume centres can achieve equally high SFRs and safety profiles as high-volume centres. The findings of this review may therefore support increased uptake of URS in centres performing fewer procedures each year.

\section{Compliance with Ethical Standards}

Conflict of Interest Shazna Rob, Patrick Jones, Amelia Pietropaulo, Stephen Griffin and Bhaskar K. Somani each declare no potential conflicts of interest.

Human and Animal Rights and Informed Consent This article does not contain any studies with human or animal subjects performed by any of the authors.

Open Access This article is distributed under the terms of the Creative Commons Attribution 4.0 International License (http:// creativecommons.org/licenses/by/4.0/), which permits unrestricted use, distribution, and reproduction in any medium, provided you give appropriate credit to the original author(s) and the source, provide a link to the Creative Commons license, and indicate if changes were made.

\section{References}

Papers of particular interest, published recently, have been highlighted as:

- Of importance

•- Of major importance

1. Sharma AP, Filler G. Epidemiology of pediatric urolithiasis. Indian J Urol: IJU : J Urol Soc India. 2010;26(4):516-22. https://doi.org/ 10.4103/0970-1591.74450.

2. Geraghty R, Jones P, Somani BK. Worldwide trends of urinary stone disease treatment over the last two decades: a systematic review. J Endourol. 2017;31(6):547-56. This paper shows a growing world-wide trend of intervention for stone disease, which has grown significantly for ureteroscopy over the last two decades

3. Ritchey M, Patterson DE, Kelalis PP, Segura JW. A case of pediatric ureteroscopic lasertripsy. J Urol. 1988;139(6):1272.

4. Al Busaidy SS, Prem AR, Medhat M. Paediatric ureteroscopy for ureteric calculi: a 4-year experience. Br J Urol. 1997;80:797-801.

5. Bassiri A, Ahmadnia H, Darabi MR. Transureteral lithotripsy in pediatric practice. J Endourol. 2002;16:257-60.

6. Schuster TG, Russell KY, Bloom DA. Ureteroscopy for the treatment of urolithiasis in children. J Urol. 2002;167:1813-6.

7. Dogan HS, Tekgul S, Akdogan B. Use of the holmium:YAG laser for ureterolithotripsy in children. BJU Int. 2004;94(1):131-3.

8. Satar N, Zeren S, Bayazit Y. Rigid ureteroscopy for the treatment of ureteral calculi in children. J Urol. 2004;172:298-300.

9. Bussaidy A, Prem AR, Medhat M. Ureteric calculi in children: preliminary experience with holmium:YAG laser lithotripsy. BJU Int. 2004;93(9):1318-23.

10. Minevich E, Rousseau MB, Wacksman J. Pediatricureteroscopy: technique and preliminary results. J Pediatr Surg. 1997;32:571-4.

11. Raza A, Smith G, Moussa S. Ureteroscopy in the management of pediatric urinary tract calculi. J Endourol. 2005;19:151-8.

12. Thomas JC, DeMarco RT, Donohoe JM. Pediatricureteroscopic stone management. J Urol. 2005;174:1072-4.

13. Assmy EL, Hafez AT, Eraky I. Safety and outcome of rigid ureteroscopy for management of ureteral calculi in children. $\mathrm{J}$ Endourol. 2006;20(4):252-5. 
14. Gedik A, Orgen S, Akay AF. Semi-rigid ureterorenoscopy in children without ureteral dilatation. Int Urol Nephrol. 2008;40:11-4.

15. Smaldone MC, Cannon GM Jr, Wu HY. Is ureteroscopy first line treatment for pediatric stone disease? J Urol. 2007;178:2128-31.

16. Erturhan S, Yağci F, Sarica K. Ureteroscopic management of ureteral calculi in children. J Endourol. 2007;21(4):397-400.

17. Corcoran AT, Smaldone MC, Mally D, et al. When is prior ureteral stent placement necessary to access the upper urinary tract in prepubertal children? J Urol. 2008;180(4 Suppl):1861e3.

18. Tanaka ST, Makari JH, Pope JC 4th. Pediatric ureteroscopic management of intrarenal calculi. J Urol. 2008;180:2150-3.

19. Kim SS, Kolon TF, Canter D. Pediatric flexible ureteroscopic lithotripsy: the children's hospital of Philadelphia experience. J Urol. 2008;180:2616-9.

20. Yeow WC, Pemberton R, Barker A. Flexible ureterorenoscopy and laser lithotripsy in children. J Indian Assoc Pediatr Surg. 2009;14(2):63e5.

21. Tanriverdi O, Silay MS, Kendirci M. Comparison of ureteroscopic procedures with rigid and semirigid ureteroscopes in pediatric population: does the calibre of instrument matter? Pediatr Surg Int. 2010;26:733-8.

22. Turunc T, Kuzgunbay B, Gul U. Factors affecting the success of ureteroscopy in management of ureteral stone diseases in children. J Endourol. 2010;24:1273-7.

23. Ghazaleh LA, Shunaigat AN, Budair Z. Retrograde intrarenal lithotripsy for small renal stones in prepubertal children. Saudi J Kidney Dis Transpl. 2011;22:492-6.

24. Nerli RB, Patil SM, Guntaka AK. Flexible ureteroscopy for upper ureteral calculi in children. J Endourol. 2011;25:579-82.

25. Dogan HS, Onal B, Satar N. Factors affecting the complication rates of ureteroscopic lithotripsy in children: results of multiinstitutional retrospective analysis by Pediatric Stone Disease Study Group of Turkish Pediatric Urology Society. J Urol. 2011;186:1035-40. One of the largest papers on paediatric ureteroscopy, which shows operative time as an important predictor of complications in paediatric stones

26. Yucel S, Akin Y, Kol A. Experience on semirigid ureteroscopy and pneumatic lithotripsy in children at a single center. Worl J Urol. 2011;29(6):719-23.

27. Atar M, Bodakci MN, Sancaktutar AA. Comparison of pneumatic and laser lithotripsy in the treatment of pediatric ureteral stones. $\mathrm{J}$ Pediatr Urol. 2013;9:308-12.

28. Resorlu B, Unsal A, Tepeler A. Comparison of retrograde intrarenal surgery and mini-percutaneous nephrolithotomy in children with moderate-size kidney stones: results of multi-institutional analysis. Urology. 2012;80(3):519e23.
29. Jurkiewicz B, Ząbkowski T, Samotyjek J. Ureterolithotripsy in a paediatric population: a single institution's experience. Urolithiasis. 2014;42(2):171-6.

30. Erkurt B, Caskurlu T, Atis G. Treatment of renal stones with flexible ureteroscopy in preschool are children. Urolithiasis. 2014;42(3):241e5.

31. Chedgy ECP, Griffin SJ, Dyer JP et al. Ureteroscopy for paediatric renal tract stones - outcomes from a tertiary European centre. Urol Int 2015;95(3):320-3.

32. Sen $\mathrm{H}$, Seckiner I, Bayrak O, et al. Treatment alternatives for urinary system stone disease in preschool aged children: results of 616 cases. J Pediatric Urol. 2015;11(1):44.e1-34.e5.

33.• Featherstone NC, Somani BK, Griffin SJ. Ureteroscopy and laser stone fragmentation (URSL) for large $(\geq 1 \mathrm{~cm})$ paediatric stones: outcomes from a university teaching hospital. J Pediatr Urol. 2016 Aug 24. This paper shows the role of ureteroscopy for large stones in paediatric patients with excellent outcomes and is a benchmark paper for treatment of large paediatric stones.

34. Gökce MI, Telli O, Özkıdık M, et al. Evaluation of postoperative hydronephrosis following ureteroscopy in pediatric population: incidence and predictors. Urology. 2016;93:164-9.

35. Iqbal N, Hussain I, Waqar S, et al. Ureteroscopy for management of ureteric stones in children-a single centre experience. J Coll Physicians Surg Pak: JCPSP. 2016;26(12):984-8.

36. Utanğaç MM, et al. Effectiveness of ureteroscopy among the youngest patients: one centre's experience in an endemic region in Turkey. J Pediatr Urol. 2017;13(1):37-e1.

37. Guven S, Basiri A, Varshney AK, et al. Examining pediatric cases from the clinical research office of the Endourological Society Ureteroscopy Global Study. Urology. 2017;101:31-7.

38. Bhageria A, Nayak B, Seth A. Paediatric percutaneous nephrolithotomy: single-centre 10-year experience. J Pediatr Urol. 2013;9:472-5.

39. Jones P, Bennett G, Aboumarzouk OM, et al. Role of minimally invasive PCNL techniques: micro and ultra-mini PCNL $(<15 \mathrm{Fr})$ in the paediatric population - a systematic review. J Endourol. 2017; https://doi.org/10.1089/end.2017.0136.

40. Anagnostou T, Tolley D. Management of ureteric stones. Eur Urol. 2004;45(6):714-21.

41. Utanğaç MM, Sancaktutar AA, Tepeler A. Micro-ureteroscopy for the treatment of distal ureteral calculi in children. J Pediatr Surg. 2017;52(3):512-6.

42. Somani BK, Aboumarzouk O, Srivastava A, Traxer O. Flexible ureterorenoscopy: tips and tricks. Urol Ann. 2013;5(1):1-6.

43. Rukin NJ, Somani BK, Patterson J, et al. Tips and tricks of ureteroscopy: consensus statement Part II. Advanced ureteroscopy. Cent Eur J Urol. 2016;69(1):98-104. 